\title{
Penjadwalan Hafalan Alquran dengan Algoritma Genetika
}

\author{
Abdul Aziz Alfaraby, Atiqah Meutia Hilda, \& Mia Kamayani \\ Universitas Muhammadiyah Prof. Dr. Hamka, Jl. Tanah Merdeka No.6 Rambutan, Jakarta Timur 13830 \\ Telp. (021) 8400941 \\ E-mail: Abdulazizalfaraby@gmail.com
}

\begin{abstract}
Abstrak - Jadwal merupakan tahapan yang paling menentukan keberhasilan suatu hafalan Alquran. Hal ini dikarenakan jadwal adalah tahap ketergantungan antar aktivitas yang membangun secara keseluruhan. Pemecahan masalah jadwal yang baik dari suatu hafalan Alquran merupakan salah satu faktor keberhasilan dalam pelaksanaannya, dan menerapkan algoritma genetika untuk memecahkan masalah dalam jadwal hafalan Alquran serta dapat menjadi solusi dalam menangani masalah dalam mengatur jadwal secara otomatis. Algoritma genetika merepresentasikan kandidat solusi optimasi jadwal ke dalam kromosom-kromosom secara acak, lalu dievaluasi menggunakan fungsi fitness dan seterusnya dilakukan seleksi. Metode seleksi yang digunakan dalam penelitian ini adalah metode seleksi roda roulette, kemudian dilakukan pindah silang dan mutasi. Pada setiap generasi, kromosom dievaluasi berdasarkan nilai fungsi fitness. Setelah beberapa generasi maka algoritma genetika akan menghasilkan kromosom terbaik, yang merupakan solusi optimal. Pengujian yang dilakukan meliputi pengujian blackbox. Hasil dari sistem jadwal hafalan Alquran menggunakan algoritma genetika adalah jadwal kegiatan-kegiatan dalam sebuah hafalan dalam waktu satu minggu, dan berdasarkan hasil pengujian performansi yang dilakukan sebanyak 6 kali dapat disimpulkan bahwa algoritma genetika membutuhkan waktu yang lama jika nilai iterasinya besar, karena dalam algoritma ini terdapat proses penggenerasian.
\end{abstract}

Kata kunci: Algoritma Genetika, Jadwal Hafalan Alquran, Optimasi, kromosom

\section{Pendahuluan}

Jadwal hafalan Alquran merupakan kegiatan yang sangat penting untuk dapat terlaksananya sebuah proses hafalan yang baik bagi para hafalan Alquran. Sebuah jadwal yang baik adalah sebuah jadwal yang dapat dilakukan oleh seluruh pihak yang terkait dalam kegiatan hafalan Alquran, tidak hanya bagi anak-anak tapi juga untuk orang dewasa. Adapun kendala yang dihadapi ketika menyusun sebuah jadwal yang baik. Jadwal hafalan Alquran di Yayasan Markaz Alquran merupakan masalah yang sulit untuk dipecahkan. Permasalahan jadwal ini, banyak ditemukan di kalangan anak-anak dan orang dewasa karena kesibukan mereka.

Adapun kendala yang dihadapi ketika membuat jadwal hafalann Alquran. Beberapa batasan yang ada dalam jadwal hafalan Alquran apabila tidak diperhitungkan dengan baik akan menyebabkan sulitnya melakukan jadwal yang tepat dan baik. Beberapa kebutuhan dari para hafalan Alquran yang dapat menjadi pertimbangan dalam melakukan jadwal.

Masalah-masalah jadwal yang terjadi di Yayasan Markaz Alquran tersebut, dapat diminimalisir dengan perhitungan jadwal yang tepat. Selain itu, juga mempertimbangkan seluruh aspek yang berkaitan dengan kegiatan hafalan Alquran di Yayasan Markaz Alquran.

Dengan adanya masalah jadwal hafalan Alquran di Yayasan Markaz Alquran, maka akan dibahasa bagaimana memecahkan masalah yang ada dalam jadwal dengan suatu metode algoritma yaitu Genetic Algorithm (Algoritma
Genetika). Algoritma genetika cukup baik untuk digunakan dalam jadwal. Algoritma genetika merupakan salah satu jalan untuk memecahkan masalah yang cukup besar dengan solusi yang cukup baik meskipun masalah tersebut membutuhkan waktu eksekusi yang lama bila dilakukan secara manual

\section{Dasar Teori}

Algoritma genetika adalah sebuah teknik optimasi yang berdasarkan pada proses evolusi alam. Di alam, kromosom yang terbaik akan bertahan hidup sehingga generasi berikutnya akan lebih baik karena kromosom pada generasi tersebut diturunkan dari orang tua yang baik pula. Konsep yang sama dikembangkan untuk penyelesaian masalah dengan cara mencari himpunan solusi terbaik yang betahan hidup dan melakukan rekombinasi solusi yang kurang baik untuk mendapatkan kromosom lain yang lebih baik pada generasi berikutnya.

Proses algoritma genetika terdiri dari beberapa langkah, yaitu pengkodean (encoding), seleksi (selection), persilangan (crossover), mutasi (mutation), decoding. Pertama-tama, proses encoding adalah suatu proses kodifikasi atas solusi dari permasalahannya. Hasil encoding adalah berbentuk string yang merupakan representasi dari suatu kromosom. Proses selection menentukan cromosom mana yang tetap tinggal pada generasi berikutnya. Proses crossover akan menghasilkan kromosom baru yang merupakan pengganti dari kromosom 
yang hilang sehinga total kromosom pada satu generasi berjumlah tetap. Proses mutation memungkinkan terjadinya kromosom baru secara unpredictable. Proses terakhir adalah decoding yaitu mengambil makna dari hasil kromosom terbaik untuk menjawab permasalahannya.

\section{A. Ecoding}

Proses encoding adalah salah satu proses yang sulit dalam algoritma genetika. Hal ini disebabkan karena proses encoding untuk setiap permasalahan berbeda-beda karena tidak semua teknik encoding cocok untuk setiap permasalahan. Proses encoding menghasilkan string yang kemudian disebut kromosom. String terdiri dari sekumpulan bit. Bit ini dikenal sebagai gen. Jadi satu kromosom terdiri dari sejumlah gen.

Ada bermacam- macam teknik encoding yang dapat dilakukan dalam algoritma genetika. Beberapa teknik-teknik encoding itu antara lain adalah binary encoding, permutation encoding, value encoding serta tree encoding. Teknik encoding yang digunakan pada jadwal hafalan Alquran adalah permutation encoding. Selain digunakan pada jadwal hafalan Alquran, teknik ini juga dapat digunakan pada Task Ordering Problem [1]. Pada permutation encoding, kromosom-kromosom adalah kumpulan angka yang mewakili posisi dalam sebuah rangkaian. Pada jadwal hafalan Alquran, kromosom mewakili waktu. Jadi apabila satu kromosom berbentuk sebagai berikut $P I=\left(\mathrm{X}_{1}, \mathrm{X}_{2}, \mathrm{X}_{3}, . ., \mathrm{X}_{\mathrm{n}}\right)$ berarti waktu bergerak dari waktu $X_{1}$ ke $X_{2}$ dst hingga ke waktu ke $X_{n}$.

\section{B. Proses Seleksi}

Proses seleksi adalah proses yang memegang peranan penting dalam algoritma genetika. Proses seleksi ini digunakan agar hanya kromosom-kromosom yang berkualitas yang dapat melanjutkan peranannya dalam proses algoritma genetika berikutnya. Ada bermacammacam teknik untuk melakukan proses seleksi pada suatu permasalahan. Teknik seleksi yang akan digunakan tergantung pada permasalahan yang akan diselesaikan. Ada bermacam-macam teknik seleksi, diantaranya adalah Roulette Wheel Selection, Rank Base Selection, dan Steady State Selection [2].

Proses penseleksian pada makalah ini menggunakan teknik roda putar atau disebut Roulette Wheel Selection. Pada proses penseleksian digunakan suatu parameter yang disebut kesesuaian atau fitness. Fitness digunakan untuk menentukan seberapa baik kromosom akan bertahan hidup. Makin tinggi nilai fitness, $0 £$ fitness $£ 1$, suatu kromosom maka makin baik kromosom itu akan bertahan hidup. Nilai fitness tertinggi merepresentasikan jawab terbaik atas persoalan itu sendiri. Penentuan berapa besar nilai fitness suatu kromosom berdasarkan fungsi fitness yang didefinisikan tersendiri. Untuk makalah ini maka fungsi fitness didefinisikan [3] pada gambar 1.

$$
\begin{gathered}
\text { Fitness }=\frac{1}{\text { Total } \text { jarak }} \ldots \ldots \ldots \ldots \ldots \ldots . . .(1) \\
\text { Gambar 1. Rumus fitness }
\end{gathered}
$$

Pada Roulette Wheel Selection, hanya kromosom yang mempunyai nilai fitness yang tinggilah yang dapat bertahan pada generasi berikutnya sebaliknya yang mempunyai nilai fitness rendah akan hilang pada generasi berikutnya. Untuk mempertahankan jumlah kromosom tetap pada satu generasi maka perlu dibangkitkan cromosom baru yang merupakan hasil penyilangan dari kromosom yang hidup. Untuk itu dilakukan proses rekombinasi.

\section{Proses Rekombinasi}

Proses rekombinasi atau yang lebih dikenal dengan nama proses crossover adalah menyilangkan dua kromosom sehingga membentuk kromosom baru yang harapannya lebih baik dari pada induknya. Tidak semua kromosom pada suatu populasi akan mengalami proses rekombinasi. Kemungkinan suatu kromosom mengalami proses rekombinasi didasarkan pada probabilitas crossover yang telah ditentukan terlebih dahulu. Probabilitas crossover menyatakan peluang suatu cromosom akan mengalami crossover.

Teknik rekombinasi yang digunakan adalah offspring Teknik ini diawali dengan membangkitkan dua bilangan acak. Kemudian gen yang berada diantara kedua bilangan acak akan disalin ke offspring dengan posisi yang sama. Langkah berikutnya untuk mendapatkan offspring pertama adalah mengurutkan gen yang berada pada parent kedua dengan urutan gen yang berada pada posisi setelah bilangan acak kedua diikuti dengan gen yang berada pada posisi sebelum bilangan acak pertama dan diakhiri dengan gen yang berada pada posisi diantara kedua bilangan acak. Kemudian gen yang telah diurutkan tersebut dibandingkan dengan offspring pertama. Apabila gen tersebut ada pada offspring kedua maka abaikan gen tersebut dari urutan itu. Kemudian masukkan urutan yang baru saja didapat pada offspring dengan cara memasukkan urutan gen pada posisi setelah bilangan acak kedua terlebih dahulu dan sisanya dimasukkan pada posisi sebelum bilangan acak pertama. Begitu juga untuk menghasikan offspring kedua. Contoh crossover adalah sebagai berikut : [4]

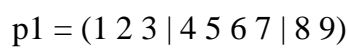

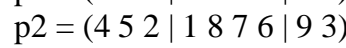

$$
\begin{aligned}
& \text { => copy the selected segments } \\
& \mathrm{o} 1=(\mathrm{x} \times \mathrm{x}|4567| \mathrm{x} x) \\
& \mathrm{o} 2=(\mathrm{x} \times \mathrm{x}|18876| \mathrm{xx}) \\
& =>\text { the seq of } \mathrm{p} 2: 9-3-4-5-2-1-8-7-6
\end{aligned}
$$

Remove 4, 5, 6, 7 in the seq and put it in o1 the remaining seq : 9-3-2-1-8

$$
\mathrm{o} 1=(\mathrm{x} \times \mathrm{x}|4567| \mathrm{x} \mathrm{x})
$$

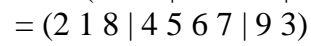

construct o2 in the same way:

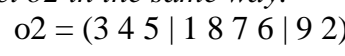




\section{Proses Mutasi}

Proses mutasi ini dilakukan setelah proses rekombinasi dengan cara memilih kromosom yang akan dimutasi secara acak, dan kemudian menentukan titik mutasi pada kromosom tersebut secara acak pula. Banyaknya kromosom yang akan mengalami mutasi dihitung berdasarkan probabilitas mutasi yang telah ditentukan terlebih dahulu [4]. Apabila probabilitas mutasi adalah $100 \%$ maka semua kromosom yang ada pada populasi tersebut akan mengalami mutasi. Sebaliknya, jika probabilitas mutasi yang digunakan adalah $0 \%$ maka tidak ada kromosom yang mengalami mutasi pada populasi tersebut.

Ada bermacam-macam teknik mutasi yang dapat digunakan untuk menyelesaikan suatu masalah dengan algoritma genetika. Seperti pada teknik rekombinasi, teknik mutasi juga dirancang untuk digunakan pada suatu masalah yang spesifik sehingga tidak setiap teknik mutasi dapat diterapkan pada suatu masalah yang akan diselesaikan. Selain itu, teknik mutasi yang digunakan juga harus sesuai dengan teknik encoding yang digunakan untuk menyelesaikan permasalahan tersebut. Beberapa teknik mutasi yang dapat digunakan dalam penyelesaian penjadwaln hafalan Alquran adalah inversion mutation, insertion mutation, dan reciprocal mutation.

Teknik mutasi yang digunakan dalam makalah adalah teknik insertion mutation. Teknik ini diawali dengan memilih dua bilangan acak kemudian gen yang berada pada posisi bilangan acak pertama ditukar dengan gen yang berada pada bilangan acak kedua.[5]

\section{Metodologi Penelitian}

\section{A. Alur algortima Genetika}

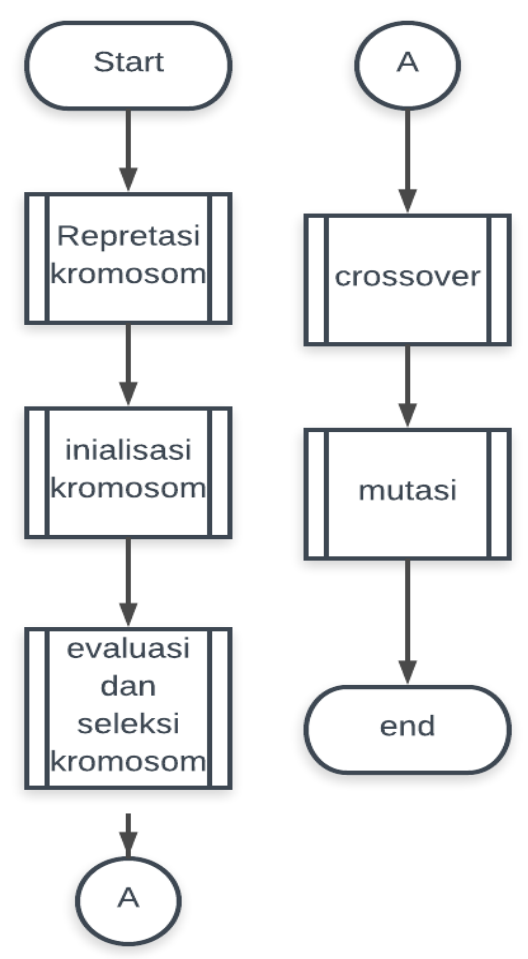

Gambar 2. Alur Algoritma Genetika
Aliran proses algoritma genetika mempunyai beberapa prosedur utama seperti repretasi kromosom, inilialisasi kromosom, evaluasi dan seleksi, pindah silang dan yang terakhir mutasi. digambarkan pada Gambar 2.

1. Representasi dan Inisialisasi Populasi Awal Menentukan populasi awal adalah proses membangkitkan sejumlah kromosom secara acak (random). Pada penelitian ini, sebuah kromosom menyatakan sebuah solusi jadwal. Kromosom terdiri dari kumpulan gen yang berisi informasi saat pelaksanaan suatu kegiatan atau pekerjaan hafalan Alquran. Panjang kromosom adalah n, dengan n adalah banyaknya kegiatan atau pekerjaan seperti gambar 3. [6]

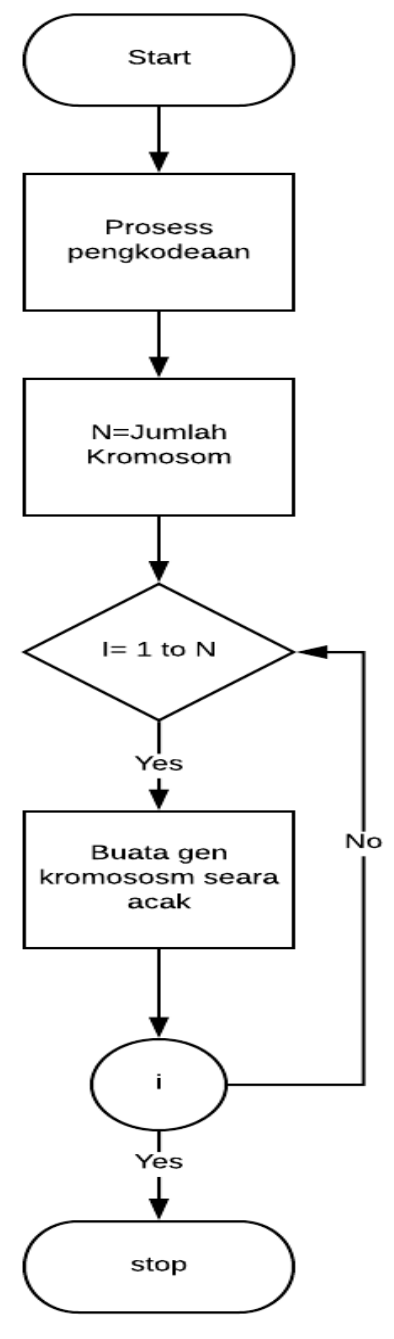

Gambar 3 Repretasi dan Pembentukan Populasi Awal.

\section{Evaluasi Fungsi Fitness}

Suatu kromosom dievaluasi berdasarkan suatu fungsi tertentu sebagai ukuran performansinya. Di dalam evolusi alam, individu yang bernilai fitness tinggi yang akan bertahan hidup. Sedangkan individu yang bernilai fitness rendah akan mati. Fungsi yang digunakan untuk mengukur nilai kecocokan atau derajat optimalitas suatu kromosom disebut dengan fitness function. Nilai yang dihasilkan dari fungsi tersebut menandakan seberapa optimal solusi yang diperoleh. 


\section{Seleksi}

Proses seleksi yang dilakukan menggunakan seleksi roda roulette (Roulette Wheel Selection). Adapun langkah-langkah proses seleksi ini dapat dilihat pada gambar 4.

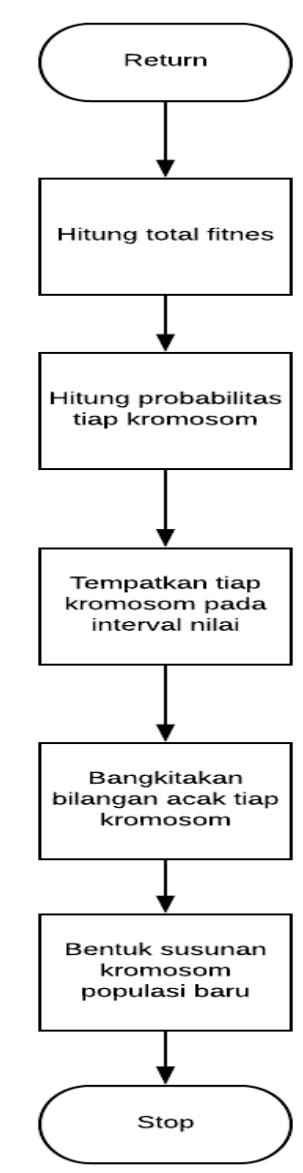

Gambar 4. Flowchart Proses Seleksi.

4. Pindah Silang (crossover)

a. Secara umum, langkah-langkah proses crossover ditunjukkan pada Gambar 5 dapat dijelaskan bahwa:

b. Pertama, tentukan probabilitas persilangan $\mathrm{P}(\mathrm{c})$.

c. Bilangan acak R(i) yang dibangkitkan untuk setiap kromosom pada proses seleksi dibandingkan dengan $\mathrm{P}(\mathrm{c})$.

d. Jika R(i) kurang dari $\mathrm{P}(\mathrm{c})$, maka pilih kromosom tersebut sebagai calon induk yang akan dikenai operasi persilangan.

e. Tentukan titik potong secara acak tergantung panjang kromosom dan lakukan operasi persilangan pada semua pasangan kromosom secara berurutan, yaitu kromosom 1 akan disilangkan dengan kromosom 2, kromosom 2 dengan kromosom 3 , begitu seterusnya.

f. Selesai

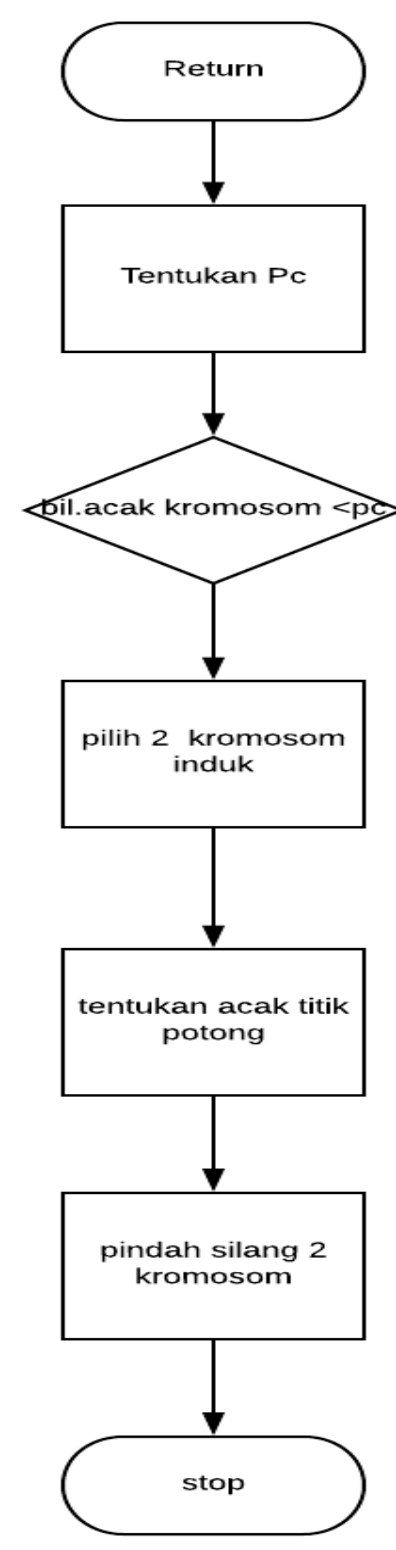

Gambar 5 Flowchart Proses Pindah Silang

5. Mutasi

Proses mutasi adalah suatu proses kemungkinan memodifikasi informasi gen-gen pada suatu kromosom. Perubahan ini dapat membuat solusi duplikasi memiliki nilai fitness lebih rendah maupun lebih tinggi daripada solusi induknya. Tetapi jika diperoleh solusi dengan nilai fitness yang lebih rendah maka bisa jadi pada iterasi berikutnya diperoleh solusi hasil mutasi yang lebih baik nilai fitnessnya daripada solusi induknya. Secara detil, flowchart proses ini ditunjukkan pada Gambar 6. 


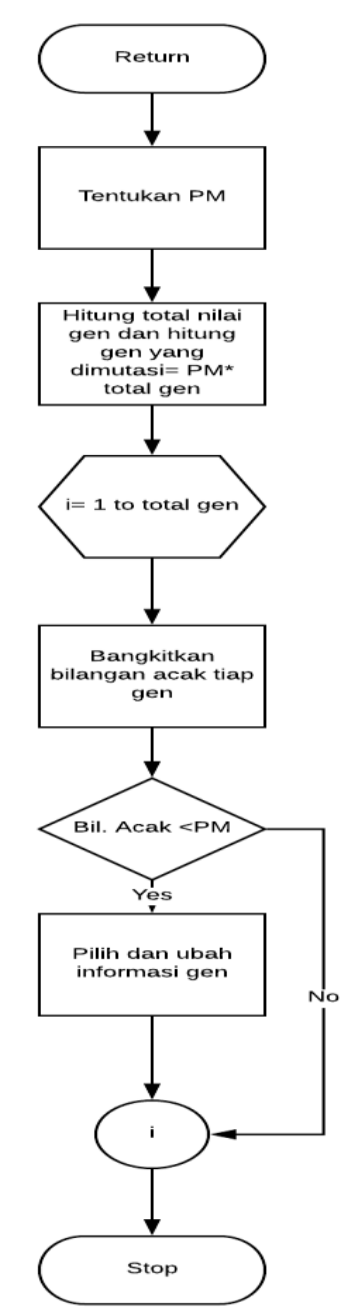

Gambar 6 Flowchart Proses Mutasi

Setelah proses berhenti, kromosom hasil mutasi akan dievaluasi. Apabila masih ditemukan kromosom yang mengandung pelanggaran dari evaluasi yang dilakukan, maka akan kembali dilakukan proses crossover dan mutasi sampai sejumlah kromosom yang tersisa habis dan tidak mengandung pelanggaran lagi.

\section{Elitism}

Proses ini adalah untuk membuat salinan (copy) individu bernilai fitness tertinggi agar tidak hilang selama proses evolusi.

7. Kondisi Selesai

Kondisi selesai yang dapat menghentikan proses algoritma genetika ini adalah jika jumlah generasi atau iterasi maksimum telah tercapai. [7]

\section{Hasil Dan Pembahasan}

Pada persoalan algoritma genetika jadwal hafalan Alquran ada beberapa data yang dibutuhkan untuk mempermudah proses penetapan dan perhitungan jadwal hafalan Alquran membutuhkan data yang tertera pada tabel 1
Tabel 1. Data untuk proses algoritma genetika

\begin{tabular}{|l|l|l|l|}
\hline NO & \multicolumn{1}{|c|}{ Data proses } & Kode & $\begin{array}{c}\text { Jumlah } \\
\text { Data }\end{array}$ \\
\hline 1 & Data Waktu & A & 30 \\
\hline 2 & Data Hari & B & 6 \\
\hline 3 & Data Mata Hafalan & C & 10 \\
\hline 4 & Data Ruang & D & 10 \\
\hline
\end{tabular}

Berdasarkan data pada tabel 5.1 maka dapat buat rumus algoritma genetika dengan $1 *$ data waktu $+2 *$ data hari + $3 *$ data matahafalan+ $4 *$ data ruang dan dengan total banayaknya data waktu maka di dapat lah rumus dengan persamaan diatas yang di tuliskan pada rumus persaaan 5.1

$$
“ a+2 b+3 c+4 d=30 "(\text { persamaan 5.1) }
$$

Maka mencari nilai a, b, c, dan $\mathbf{d}$ yang memenuhi persamaan 1, digunakan algoritma genetika untuk menyelesaikan permasalahan data pada Tabel 1. Flowchart dari algoritma genetika untuk menyelesaikan permasalahan tersebut di perlukan tahapan-tahapan pada permasalahan algoritma genetika jadwal mulai dari permasalahan, pembentukan kromosom, inialisasi kromosom, evaluasi kromosom, seleksi kromosom, crossover, mutasi, proses dekoding, dan solusi permasalahan yang dapat dilihat gambar 7 .

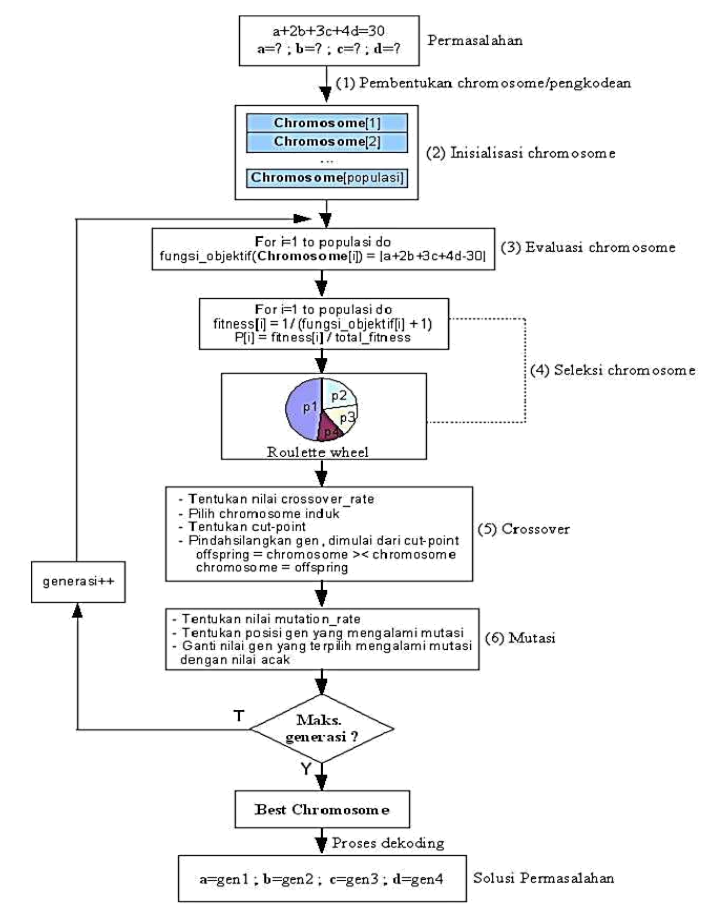

Gambar 7 Flowchart algoritma genetika jadwal hafalan Alquran

\section{A. Analisa Data Keluaran (Output)}

Output dari sistem jadwal hafalan Alquran ini berupa jadwal setiap kegiatan. Data keluaran juga ditampilkan dalam bentuk tabel kerja agar lebih jelas serta mudah dimengerti sebagai acuan dalam pengerjaan hafalan Alquran pada tabel Adapun 
perbedaan data antara hafalan alquran remaja yang di tampilkan tabel 2 dan hafalan alquran orang tua pada tabel 3. [8]

Tabel 2 variable dan data set pada remaja

\begin{tabular}{|l|l|}
\hline Variable hari & Data set \\
\hline Senin & Merojaah \\
\hline Selasa & Hafalan baru \\
\hline Rabu & Teori \\
\hline Kamis & Mentadaburi \\
\hline Jumat & Setoran \\
\hline Sabtu & Tilawah \\
\hline Minggu & \\
\hline
\end{tabular}

Tabel 3 variable dan data set pada orang tua

\begin{tabular}{|l|l|}
\hline Variable hari & Data set \\
\hline \multirow{4}{*}{ Today } & Murojaah \\
& \\
\cline { 2 - 2 } & Tilawah \\
\hline
\end{tabular}

Dalam data set hafalan alquran pada remaja dikarenakan banyak variable yang dibutuhkan maka kemungkinan jadwal gagal sangat kecil dibandingkan dengan data jadwal orang tua yang minimal data cossover dan mutasi lebih dari 100 untuk menghasilakan jadwal yang sukses berikut gambar pada lampiran 1 .

\section{B. Analisa Kebutuhan Fungsi}

Sistem jadwal hafalan Alquran membutuhkan beberapa fungsi agar dapat digunakan sebagaimana mestinya oleh user, dan memberikan hasil yang optimal. Fungsi yang dibutuhkan user adalah sebagai berikut :

a. Fungsi input data, terdiri dari data hafalan Alquran, data kegiatan, dan data untuk proses algoritma genetika,

b. Fungsi proses, terdiri dari proses jadwal hafalan Alquran.

c. Fungsi pencetakan laporan, digunakan untuk menampilkan dan mencetak laporan berupa kalender kerja hafalan Alquran yang dihasilkan oleh sistem. Sedangkan fungsi-fungsi yang dibutuhkan oleh sistem adalah sebagai berikut :

1. Fungsi Inisialisasi populasi awal

Fungsi ini digunakan untuk penginputan dan inisialisasi populasi mengacak semua data waktu pelaksanaan kegiatan menjadi kromosom-kromosom.

2. Fungsi evaluasi dan seleksi kromosom

Fungsi ini digunakan untuk menilai bagus tidaknya sebuah kromosom yang nantinya dapat menjadi solusi dari permasalahan.

3. Fungsi crossover
Fungsi ini digunakan untuk melakukan crossover (penyilangan) antara dua kromosom yang telah dievaluasi sebelumnya.

4. Fungsi mutasi

Fungsi ini digunakan untuk mengubah susunan gen yang terdapat dalam kromosom dengan mengganti nilai gen.

5. Fungsi setting (pengaturan)

Dalam fungsi ini terdapat fasilitas untuk menentukan parameter-parameter dalam algoritma genetika, seperti probabilitas crossover dan probabilitas mutasi. Akan tetapi parameter ini juga memiliki nilai default untuk mengantisipasi bila perubahan nilai parameter menghasilkan kinerja yang kurang memuaskan.

\section{Tahapan Implementasi}

Tahapan implementasi merupakan tahapan dimana suatu sistem atau perangkat lunak yang telah dianalisa, dirancang dan selanjutnya akan direalisasikan sebagai serangkaian program, lalu diuji kelayakannya. Sehingga akan diketahui bahwa sistem yang dibuat sesuai dengan tujuan yang diinginkan dan dapat dioperasikan sebagaimana mestinya. Berikut ini akan dijelaskan tentang pengimplementasian sistem jadwal hafalan alquran berdasarkan analisa dan perancangan yang telah dilakukan sebelumnya.

\section{Hasil}

1. Implementasi Interface Menu Beranda

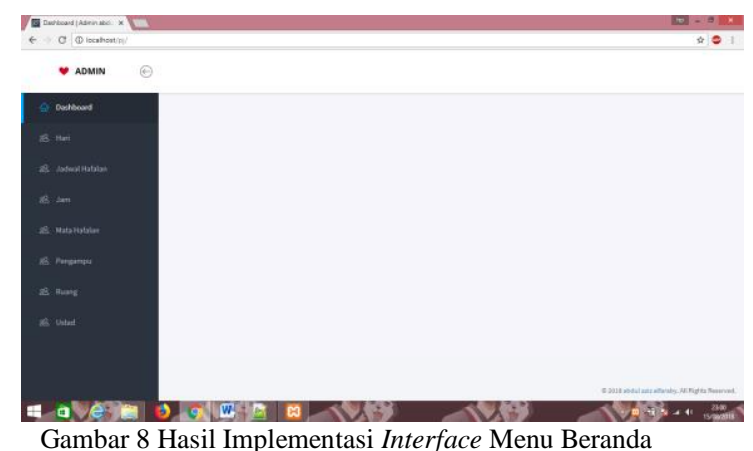

Interface pada Gambar 8 merupakan tampilan yang akan muncul pertama sekali ketika user menjalankan sistem ini.

2. Implementasi Interface Menu Hari

Menu ini menampilakan data hari mulai dari hari senin sampai dengan hari sabtu dapat di lihat pada gambar 9 . 


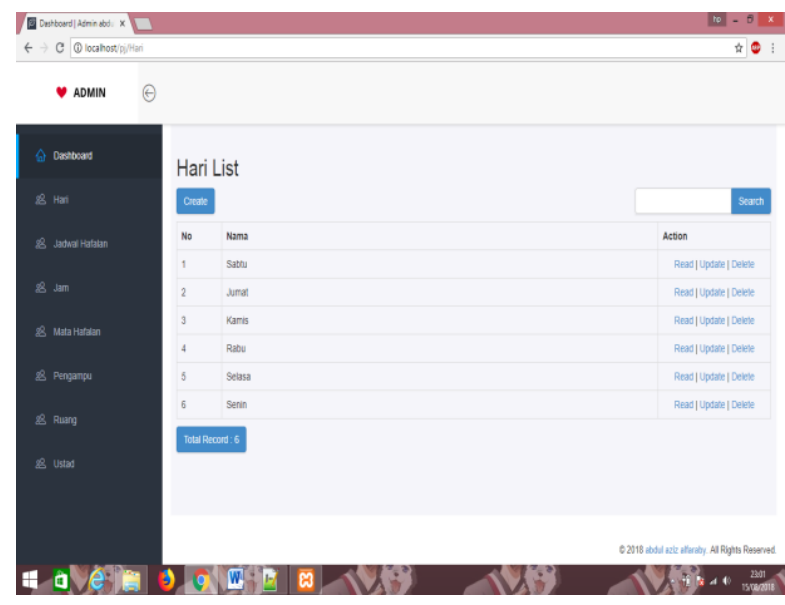

Gambar 9.Input dan Tampilan menu hari

Selanjutnya, pada Gambar 10 dapat dilihat interface dari menu jadwal hafalan yang digunakan untuk melakukan pencarian jadwal hafalan dengan menggunakan algoritma genetika dan harus memasukan beberapa data untuk melakukan proses pencarian, setelah data yang dibutuhkan sudah terinput maka pengguna dapat mengklik tombol proses. Maka jadwal kegiatan untuk menghafalkan alquran akan muncul dalam bentuk tabel.

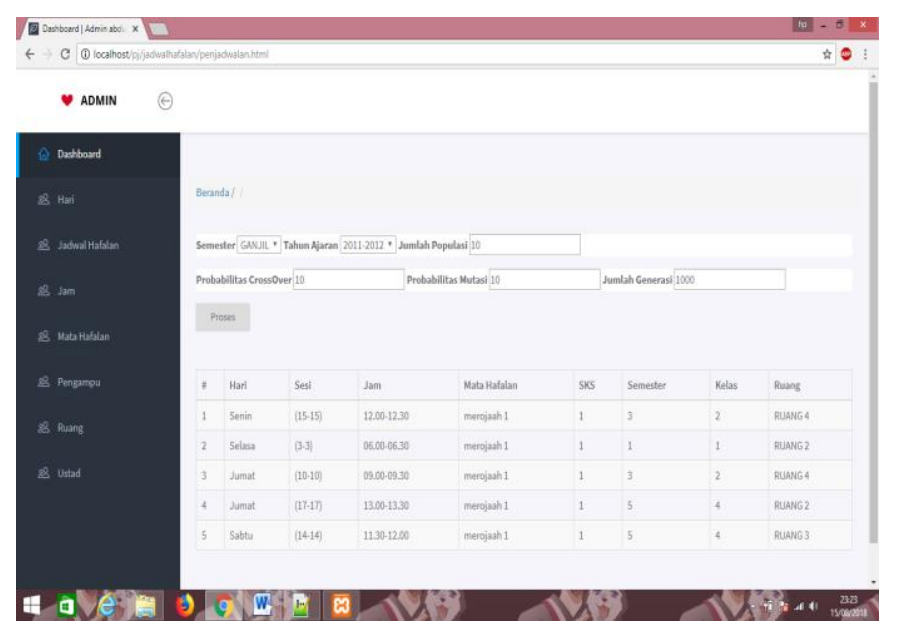

Gambar 10 Tampilan dan Proses pencarian jadwal hafalan alquran.

\section{Simpulan dan Saran}

Setelah menyelesaikan serangkaian tahapan-tahapan dalam menerapkan algoritma genetika pada sistem jadwal hafalan Alquran maka dapat ditarik kesimpulan yaitu:

1. Sistem jadwal hafalan Alquran menggunakan algoritma genetika ini telah berhasil dibangun dan diimplementasikan untuk mencari solusi jadwal yang optimal yaitu memenuhi batasan/persyaratan (constraints) dalam jadwal hafalan Alquran, mengoptimalkan efisiensi pemakaian waktu pelaksanaan setiap kegiatan.

2. Sistem jadwal hafalan Alquran ini mampu menangani operasi input data, melakukan proses jadwal hafalan Alquran secara otomatis dan menghasilkan jadwal yang optimal.
3. Algoritma genetika bekerja berdasarkan suatu bilangan acak (random) yang dibangkitkan pada masing-masing solusi sehingga menyebabkan hasil analisa akan berbeda dengan hasil pengujian menggunakan sistem yang dibangun.

4. Dari hasil user acceptance test dapat disimpulkan bahwa sistem jadwal hafalan Alquran menggunakan algoritma genetika dapat memberikan solusi jadwal kegiatan-kegiatan yang dapat menjadi alternatif keputusan bagi para hafalan Alquran.

5. Dari pengujian dua sampel data yaitu remaja dan orang tua data yang di butuhkan berbeda dan hasilnya berbeda, pada hasil output pada remaja kemungkinan peluang untuk bentrok atau terdapat fitness sangatlah kecil tetapi jika pada data orang tua membutuhkan masukan crossover dan mutasi minimal 100 untuk jadwal tidak memiliki fitness

\section{Kepustakaan}

[1] Slamat, Fauzi.“ Klasifikasi Data Karyawan Untuk Menentukan Jadwal Kerja Menggunakan Metode Decision Tree”.Skripsi, ITATS, 2012.

[2] Handoyo, Eko. "Pembangunan aplikasi penyusunan jadwal kuliah menggunakan algoritma semut'.Skripsi, Universitas Diponogoro, Semarang, 2015.

[3] Maharani, febria. "Sistem jadwal proyek menggunakan algoritma Genetika". Skripsi, jurusan teknik informatika fakultas sains dan teknologi Universitas islam negeri sultan syarif kasim pekanbaru,2013.

[4] Sam'ani. "Rancang Bangun Sistem Jadwal Perkuliahan dan Ujian Akhir Semester dengan Pendekatan Algoritma Genetika”. Tesis Pascasarjana, Universitas Diponegoro, Semarang, 2012.

[5] Suyanto. Algoritma Genetika dalam Matlab. Andi, Yogyakarta,2012.

[6] Putra, Yendrika. "Aplikasi Jadwal Perkuliahan Menggunakan Algoritma Genetika”. Skripsi Sarjana, Fakultas Sains dan Teknologi Universitas Islam Negeri SUSKA, Riau, 2012.

[7] Hartono, Jogiyanto. Analisis \& Desain Sistem Informasi: Pendekatan terstruktur teori dan praktek aplikasi bisnis. Andi Offset, Yogyakarta, 2005.

[8] Fadlisyah, Arnawan, Faisal. Algoritma Genetika.Graha Ilmu, Yogyakarta, 2009. 